\title{
ACUMULACIÓN DE CAPITAL, DESPOJO Y DISPUTAS DE ESPACIOS AGRARIOS EN BRASIL Y MÉXICO
}

\author{
ACCUMULATION OF CAPITAL, DISPOSSESSION AND DISPUTES \\ OF AGRARIAN SPACES IN BRAZIL AND MÉXICO
CUMULAÇÃO DE CAPITAL, DESAPROPRIAÇÃO E DISPUTAS
DE ESPAÇOS AGRÁRIOS NO BRASIL E NO MÉXICO \\ Agustín Ávila Romero - Universidad Intercultural de Chiapas - México \\ agustinavila@yahoo.com
}
Adriano Rodrigues de Oliveira - Universidade Federal de Goiás - Goiânia - Goiás - Brasil adriano.ufg@gmail.com

Leon Enrique Ávila Romero - Universidad Intercultural de Chiapas - México

leonenriqueavila@gmail.com

\begin{abstract}
Resumen
La acumulación de capital en América Latina ocasiona un proceso de despojo de tierras a campesinos e indígenas en diferentes naciones. Y México y Brasil se encuentran inmersos en esa dinámica pese a tener por varios años otros diseños de política económica y agropecuaria. A través de una investigación bibliográfica y de base de datos, encontramos un proceso de disputas de los espacios agrarios entre las grandes corporaciones trasnacionales y los productores rurales de ambas naciones. Así el espacio agrario se encuentra marcado por el impulso del agronegocio, el neoextractivismo y la mercantilización de la naturaleza. Se construye así una reconfiguración geográfica del capital, donde dichos países se insertan de manera subordinada en el capitalismo global. Se presenta un proceso de subsunción real del territorio al capital que conlleva a la construcción de regímenes de desapropiación en ambas naciones y el fortalecimiento de la colonialidad y la concentración y extranjerización de tierras.
\end{abstract}

Palabras clave: Despojo, campesinos, agronegocio, Brasil, México.

\section{Abstract}

The accumulation of capital in Latin America causes a process of dispossession of lands to peasants and indigenous peoples in different nations. And Mexico and Brazil are immersed in this dynamic despite having for several years other designs of economic and agricultural policy. Through a bibliographic and database research, we find a process of disputes between agrarian spaces between large transnational corporations and rural producers of both nations. Thus, the agrarian space is marked by the impulse of agribusiness, neoextractivism and the commodification of nature. Thus, a geographical reconfiguration of capital is constructed, where these countries are subordinated to global capitalism. It presents a process of real subsumption of the territory to capital that leads to the construction of regimes of expropriation in both nations and the strengthening of coloniality and the concentration and foreignization of land.

Keywords: Dispossession, peasants, agribusiness, Brazil, Mexico.

Resumo

0 acúmulo de capital na América Latina tem provocado o processo de desapropriação de terras para os

ISSN: 1984-8501 Bol. Goia. Geogr. (Online). Goiânia, v. 38, n. 2, p. 297-316, maio/ago. 2018 
camponeses e os povos indígenas em diferentes nações. 0 México e o Brasil estão submetidos à essa lógica, mesmo com adoção de políticas governamentais distintas, de governos populares que ascenderam ao poder nas últimas décadas, implementando políticas econômicas e agrícolas distintas. Por meio de revisão bibliográfica e análise de dados e informações secundárias, apresentamos um processo de disputas nos espaços agrários entre grandes corporações transnacionais e os produtores rurais das duas nações. Assim, o espaço agrário é marcado pela expansão do agronegócio, do neoextrativismo e da mercantilização da natureza. Assim, uma reconfiguração geográfica do capital é construída, submetendo esses países ao capitalismo global, caracterizada pela subsunção real do território ao capital que leva à construção de regimes de expropriação em ambas as nações e o fortalecimento da colonialidade e da concentração e estrangeirização da terra.

Palavras-chave: Espoliação, camponeses, agronegócio, Brasil, México.

\section{Introducción}

La cuestión agraria en América Latina gira alrededor de un impresionante proceso de despojo de los campesinos e indígenas de este continente. Lo que se acompaña además por el cierre de cualquier proceso de acceso a las tierras de nuevos grupos sociales, es decir, la clausura de la reforma agraria por parte de los gobiernos afines al capital internacional y una nueva concentración latifundista en muchas regiones.

En contraparte, grandes vertientes de las zonas rurales o naturales de los territorios de nuestro continente, se han convertido en nuevos espacios de valorización y búsqueda de ganancias por parte de los capitalistas. Somos testigos así de un movimiento inusitado de capitales hacia los espacios campesinos e indígenas en la búsqueda de ganancias extraordinarias. Lo cual también ha generado procesos de resistencia y de re-existencia por parte de los actores rurales con un sentido de territorialidad (Porto-Gonçalves, 2001).

Entre las líneas de explotación del capitalismo de los espacios rurales se encuentran: 1) el impulso a la reconversión productiva de la producción campesina e indígena, para coadyuvar a la subordinación alimentaria de los pobladores con la perdida de la soberanía alimentaria de nuestras naciones. A ellos se suma 2) el neoextractivismo que a través de la explotación minera, de hidrocarburos, turística, parques eólicos, gasoductos, oleoductos y de construcción de presas y de infraestructura, busca una nueva producción del espacio rural acorde a la dinámica del capitalismo global. Y 3) la mercantilización de la naturaleza a través de la creación de mecanismos de privatización de bienes comunes como el agua, la biodiversidad y diversos servicios ambientales, a ellos se suma la apropiación de las corporaciones internacionales a través de patentes de la riqueza biológica del planeta con su consiguiente valorización. 
Este artículo esta dividido en tres secciones además de esta introducción y de las conclusiones finales. En la primera sección presentamos el marco teórico acerca de los procesos vigentes en la América Latina, destacando las estrategias contemporáneas de apropiación y uso de los territorios notablemente marcadas por la desposesión y desapropiación. En la segunda sección, presentamos como esos procesos se territorializan en el Brasil, con el impulso a la commoditización/ reprimarización de la economía y la extranjerización de las tierras. En la tercera sección, analizamos la territorialización de los monopolios agroalimentarios, mineros y la expropiación de las comunidades indígenas y campesinas en el territorio mexicano.

Acumulación originaria, acumulación por desposesión y regímenes de desapropiación en América Latina

Uno de los mecanismos utilizados en esta fase de desarrollo capitalista son los megaproyectos mediante la incorporación de los territorios rurales en torno a grandes planes geoestratégicos como son el Proyecto Mesoamérica que abarca desde México hasta Colombia, ó la Iniciativa para la Integración de la Infraestructura Regional Sudamericana (IIRSA), en la que participan 12 naciones de América del Sur, en materia de construcción de infraestructura regional de energía, transporte y telecomunicaciones y que busca fundamentalmente facilitar la extracción de recursos naturales.

Ello es así por que

Los megaproyectos son una necesidad acorde con la magnitud del desarrollo del capitalismo mundial en dos sentidos: uno con producciones casi inimaginables de mercancías, para consumos excesivos de algunos sectores; y el segundo como infraestructuras, ya que el capital requiere de esas obras para mantener la maquinaria que le permite cerrar ciclos de consumo. Por ello los megaproyectos son la manifestación espacial del desarrollo del capitalismo neoliberal a escala global. (Ibarra, 2016, p. 26)

Junto con el impulso a megaproyectos somos testigos de la conformación de una clase capitalista trasnacional y un Estado trasnacional (Robinson, 2007) que imponen la agenda trasnacional en el campo de América Latina, por encima de las necesidades alimentarias, ambientales 
y socio-culturales de sus habitantes. Todo ello acompañado por una territorialidad de las corporaciones que asignan los bienes a producirse, las orientaciones y ritmos tecnológicos, el control del consumo y de los modos de vida, y el disciplinamiento de la vida social. (Ceceña, 2016)

Se construye así una reconfiguración geográfica del capital donde nuestro continente se inserta de manera subordinada en el capitalismo global, a través del impulso del extractivismo y de la expansión del agronegocio, que impulsan grandes emprendimientos mineros, agroindustriales, bioprospectivos y de infraestructura, donde la dinámica del despojo aparece siempre.

Grandes impactos en la vida campesina y ecológica de América Latina ocurren donde

[...] la transformación de los alimentos y materias primas en objetos de especulación (commodities) no constituye, por tanto, un proceso económico que provenga del funcionamiento mecánico del sistema, sino que responde a una estrategia de dominio, razón por la cual la crisis alimentaria ha beneficiado ampliamente a las empresas agroalimentarias, energéticas y financieras anglosajonas". (Rubio, 2014, p. 19)

Esta última fase de dominio geográfico y agroalimentario por parte de las empresas trasnacionales ha aumentado el despojo, la explotación, la represión y el racismo ${ }^{1}$ que enfrentan los campesinos y los indígenas del sur de nuestro planeta, por defender sus recursos naturales y sus modos de vida, ello ha planteado el surgimiento de ontologías políticas que plantean claramente el territorio y la diferencia como formas de hacer política más allá de la visiones universalizantes. (Escobar, 2014)

Así en el siglo XXI continua con mayor fuerza el proceso de subsunción de los territorios a las dinámicas del capital (Revelli, 1997). Los territorios se convierten en cuestiones estratégicas para el capital en el siglo XXI, entonces, lo que busca el capital es subordinar esos territorios a la lógica capitalista.

El control del territorio se convierte en factor productivo clave en tanto directamente genera condiciones para engendrar valor. Este es hoy el escenario de las confrontaciones más significativas entre el capital y los guardianes de la tierra, los pueblos originarios. (Rodríguez, 2015, p. 50) 
Como bien han anotado en el caso de América Latina hay momentos de sometimiento territoriales (Núñez et al., 2015). El primero correspondiente al proceso de acumulación originaria de capital que estudio Marx (1867) donde se da una separación de los campesinos de sus medios de producción y es donde a nivel de territorio se presenta el despojo de tierras y el reordenamiento territorial, lo que denominan subsunción formal del territorio al capital. Por su parte, el proceso de subsunción real del territorio al capital, implica la utilización de innovaciones tecnológicas en el proceso de producción con una intensificación sin precedentes a la agresión de la Madre Tierra -como la denominan muchos pueblos indígenas de continente-.

Así con la subsunción real del territorio el capital

[...] comienza a producir un espacio directamente a su propia medida. O sea, un espacio determinado por las exigencias soberanas de lo económico. Un espacio cortado a la medida de las exigencias productivas, un espacio directamente 'capitalista', que realiza precisamente la subsunción real del territorio a su proceso de valorización. (Revelli, 1997, p. 60).

Ejemplo de ello, es lo que observamos ahora en América Latina con la minería a cielo abierto, la construcción de hidrovías en la cuenca del Amazonas o la destrucción de la biodiversidad con las plantaciones agroforestales como la palma africana o el eucalipto en el continente.

Es relevante anotar que Mesoamérica, la región andina, la Amazonia y el Cono Sur albergan paisajes y bienes naturales, culturales y políticos que constituyen un patrimonio biogeográfico invalorable amenazado con esta reconfiguración geográfica del capital. (Porto-Gonçalves et al., 2016.)

Ello nos traslada a intentar comprender los procesos actuales de la cuestión agraria en América Latina y de la desposesión, a través de la discusión que se genera entre el entendimiento de la acumulación originaria explicada en el Capitulo 24 del Tomo I de El Capital de Marx (1867), la aseveración de David Harvey (2004) que vivimos un proceso de acumulación por desposesión y la posición de Michael Levien $(2013,2014)$ de regímenes de desapropiación, todo ello sirve para explicar la complejidad de los procesos del capitalismo global en los espacios rurales.

Marx explica claramente en El Capital, que la historia del capitalismo esta basada en el despojo violento de los medios de producción de los campesinos, y con ello, de sus modos de vida y de sus relaciones 
con la naturaleza. No es un acto económico solamente sino también la institución de nuevos mecanismos legales y de poder político, basados en la propiedad, el mercado y la plusvalía. Resalta Marx que despojo y violencia son la pareja inseparable del proceso del funcionamiento del capitalismo como un sistema mundial, donde el capital recurre de manera cíclica al mismo mecanismo de acumulación originaria en nuevos territorios y espacios rurales.

Ello es complementado por Rosa Luxemburgo (1967, p. 285) cuando afirma que

El Capital no puede desarrollarse sin los medios de producción y la fuerza del trabajo del planeta entero. Para desplegar, sin obstáculos, el movimiento de acumulación, necesita los tesoros naturales y las fuerzas de trabajo de toda la tierra. Pero estos se encuentran de hecho, en su gran mayoría, encadenados a formas de producción precapitalistas -este es el medio histórico de la acumulación de capital- surge aquí el impulso irresistible del capital a apoderarse de aquellos territorios y sociedades.

Por lo que Luxemburgo concluye basada en Marx que la lucha contra la economía natural, -entiéndase otros territorios- es fundamental para el capitalismo por lo que la dinámica de despojo y violencia forman parte del funcionamiento capitalista. Y por tanto,- anotamos nosotros- el despojo es el punto central que bombea sangre al corazón del capitalismo contemporáneo. No se habla entonces sólo de desposesión como parte de la historia colonial, sino como el motor del funcionamiento del capitalismo actual.

Por su parte, para David Harvey (2004) la tendencia del sistema capitalista a producir crisis de sobreacumulación de capital genera excedentes (expresado como sobreabundancia de mercancías en el mercado, que no pueden venderse sin pérdidas; como capacidad productiva inutilizada; o como excedentes de capital-dinero que carecen de oportunidades de inversión productiva y rentable) y excedentes de trabajo (creciente desempleo), que coexisten sin posibilidades claras de combinarse de forma útil.

Para resolver dicha tendencia a la sobreacumulación, el capital hace uso del proceso de expansión geográfica y de reconfiguración espacial que permite a otras partes del mundo -los mundos rurales-incorporarse plenamente a las dinámicas de valorización de capital y por tanto de explotación y despojo de sus prácticas económicas y sociales distintas. 
En este camino de producción del espacio desarrolla Harvey, el concepto de acumulación por desposesión, que desde su punto de vista incluye la acumulación originaria de Marx, pero también un conjunto nuevo de procesos de despojo:

[...] el énfasis en los derechos de propiedad intelectual en las negociaciones de la OMC (el denominado acuerdo TRIPS) marca los caminos a través de los cuales las patentes y licencias de materiales genéticos, plasma de semillas, y cualquier forma de otros productos, pueden ser usadas contra poblaciones enteras cuyas prácticas de manejo ambiental han jugado un papel crucial en el desarrollo de estos materiales. La biopiratería es galopante, y el pillaje del stock mundial de recursos genéticos en beneficio de unas pocas empresas multinacionales esa en marcha. La reciente depredación de los bienes ambientales globales (tierra, aire, agua) y la proliferación de la degradación ambiental, que impide cualquier cosa menos los modos capital-intensivos de producción agrícola, han resultado de la total transformación de la naturaleza en mercancía. La mercantilización de las formas culturales, las historias y la creatividad intelectual supone la total desposesión -la industria de la música se destaca por la apropiación y explotación de la cultura y la creatividad populares. La corporativización y privatización de activos previamente públicos (como las universidades), por no mencionar la ola de privatización del agua y otros servicios públicos". (Harvey, 2004, p. 114).

Los ejemplos de acumulación por desposesión según Harvey (2004), incluyen la expropiación de tierra y recursos naturales de las poblaciones campesinas, la conversión de propiedad comunal o estatal en propiedad privada, la extracción de rentas por los derechos de propiedad intelectual, la privatización de bienes sociales colectivos como la salud, la educación, y el sistema de pensiones, entre otras, este concepto así coadyuva a entender el funcionamiento del capitalismo contemporáneo.

Como bien afirman Miguel Teubal y Tomas Palmisano (2013) hay que anotar que este proceso de acumulación por desposesión está atravesado en América Latina por la colonialidad del poder y la concentración de la tierra por parte del capital financiero y agroindustrial que busca sobre todo la renta diferencial.

Esa colonialidad constitutiva, es importante, para visualizar las dinámicas capitalistas como no homogéneas entre continentes o naciones. Desde América Latina puede observarse entonces una heterogeneidad estructural que nos permite ubicar los procesos de despojo en momentos y 
lugares diferentes de acuerdo a factores políticos, económicos e ideológicos diversos y no solo dependientes del funcionamiento del capitalismo global.

Ello nos lleva a Michael Levien $(2014,2015)$ que apunta que la configuración especifica en determinado lugar puede ser comprendida como un régimen de desposesión particular. Para este autor un régimen de desposesión representa un medio institucionalizado para despojar activos a sus dueños o usuarios actuales. Para ello se requiere un Estado dispuesto a despojar en nombre de un conjunto de propósitos económicos vinculados a intereses de clase y la construcción de consenso para hacer posible el despojo.

Para Levien (2015) entender la manera como las sociedades expropian tierra y recursos naturales, y la manera como producen espacio, en diferentes configuraciones político-económicas es central, ya que existen diferencias fundamentales en el desarrollo capitalista entre diversas naciones y continentes.

En nuestro caso particular, en América Latina se ponen en marcha diversas políticas institucionales que nos hablan de dos grandes configuraciones que abren la posibilidad de hablar de regímenes de desposesión específicos, de un lado los países que aplican el consenso de Washington y la normativa neoliberal de manera ortodoxa donde destacan el caso mexicano y lo que fue la idea de los países neo-desarrollistas -hasta el golpe político/ parlamentario/jurídico/mediáticode 2016 en Brasil (Mitidiero Junior, 2017). Pasaremos a analizar primero el caso brasileño.

La etapa reciente de acumulación de capital en el Brasil: extranjerización de las tierras y commoditización de la economía

Brasil por su dimensión territorial que rebasa los 8.5 millones de $\mathrm{km} 2$ concentra una gran cantidad de recursos naturales que pueden ser sintetizados en tres dimensiones básicas que conforman su territorio: agua, tierra y subsuelo.

Es sabido que esas dimensiones del territorio brasileño son separables solamente desde el punto de vista del ejercicio abstracto del pensamiento, pues concretamente estánimbricados en la totalidad de las relaciones que se dan entre la sociedad y la naturaleza. Así el proceso de constitución del territorio brasileño, posee como característica especial 
su sumisión a los intereses coloniales de la metrópoli portuguesa en el inicio del siglo XVI.

Brasil - así como las demás naciones latino-americanas- esta marcado por las fases anteriores y posteriores a la invasión europea en su formación económica -social. De un período en que las relaciones intersubjetivas se daban por la conformación sujeto-sujeto, a través del equilibrio entre las sociedades indígenas y la naturaleza, para un período compuesto por sucesivas etapas que fueron conformando una nueva relación entre sujeto-objeto, dictada por el ritmo de acumulación impulsado por la Revolución Industrial (Núñez et. al, 2015). Se dio así, la ruptura de las relaciones armoniosas entre naturaleza y sociedad, pasándose al dominio de la primera por la segunda. Tal irrupción, significa en última instancia la aceleración del proceso de degradación de las condiciones ambientales.

La etapa reciente de acumulación de capital en el Brasil, ha sido fuertemente influenciada por las potencialidades ofrecidas por los recursos naturales que componen su territorio. Harvey (2004) apoyado en Luxemburgo(1968) desarrolla el concepto de acumulación por desposesión para explicar los dos procesos que estarían "orgánicamente vinculados": 1) la obtención de plusvalía por la alineación de los campesinos y trabajadores de los medios de producción y 2) las relaciones entre los capitalistas y los modos de producción no capitalistas, que comienzan a surgir en el escenario internacional. Todo ello para la reproducción ampliada del capital en la escala internacional, las estrategias utilizadas pueden ganar múltiples características que pasan por el fraude, la opresión, el pillaje, etc.

Por un lado, las sucesivas crisis del capital internacional, notablemente la ultima que estalló en 2008, por otro lado, las crisis alimentarias y energéticas que han desencadenado una "corrida desenfrenada" por territorios, donde exista abundancia para tierras para el cultivo de alimentos y formas alternativas de energía. Se observa así que la territorialización del capital en el espacio agrario ha constituido una importante estrategia para permitir la manutención de la reproducción ampliada, y por consiguiente, la recuperación económica de las corporaciones internacionales, que por la diversificación de sus capitales, han extendido sus tentáculos en el desarrollo del agronegocio en países de América Latina, Caribe y África Subsahariana. (CLEMENTS; FERNANDES, 2013). 
En el Brasil la reserva de tierras productivas ha desencadenado una serie de estrategias de ordenamiento del territorio tanto por parte del Estado como por las corporaciones del agronegocio. La delimitación de la región productiva de MATOPIBA (acrónimo formado por las iniciales de los estados de Maranhão, Tocantins, Piauí e Bahía) por medio del Plan de Desarrollo Agropecuario (PDA), establecido por medio del Decreto Presidencial No. 8.447 en 2015, convierte esa porción del territorio del bioma Cerrado en un gran atractivo para el capital financiero nacional e internacional. La región totaliza 73 millones de hectáreas y contempla los territorios de diversas poblaciones tradicionales (Quilombolas e Indígenas) y campesinas. (Brasil de fato, 2017)

Tal acción pone en claro el pacto establecido con el capital privado, una vez que con la regulación de esa región geoeconómica, la empresa RADAR Propiedades Agrícolas S.A. ${ }^{2}$ paso a actuar en la región con miras a especular con la propiedad de la tierra (Pitta; Mendonça, 2015). La actuación de RADAR en la bioma del Cerrado, demuestra el carácter hibrido que las corporaciones del agronegocio han asumido, una vez que COSAN S.A. -responsable por la negociaciones- es originalmente oriunda del agronegocio cañero. Esa misma empresa, crio una joint-venturepara actuar en la producción de etanol y azúcar con la petrolera Royal Dutch Shell: a Raízen -que paso a ser responsable por la producción anual de 2.2 billones de litros de etanol y 4 millones de toneladas de azucar. (Xavier; Pitta; Mendonça, 2011).

La territorialización del agronegocio cañero anclada en el binomio representado por la producción del azúcar y del etanol como agrocombustible -sector históricamente subsidiado por el Estado brasileño, notablemente a partir de Proálcool en 1975- tuvo un nuevo impulso para el avance de su frontera agrícola por medio del Plan Nacional de Agroenergía (2006-2011) que a partir de un zoneamiento agroecológico del territorio realizado por la EMBRAPA (Empresa Brasileña de Investigación Agropecuaria) estableció las áreas con aptitud para la interiorización del cultivo de caña de azúcar en los biomas del Cerrado y del Pantanal brasileño, teniendo como resultado el crecimiento de la producción cañera en estados como Goiás (908 mil hectáreas), Minas Gerais (811 mil hectáreas) e Mato Grosso do Sul (677 mil hectáreas) que pasaron a figurar respectivamente como segundo, tercero y cuarto estados mayores productores de caña de azúcar en el país, que tuvo al estado de Sao Paulo 
(4.678 millones de hectáreas) como principal productor en 2015, de un total de 8.995 millones de hectáreas cultivadas con caña de azúcar en el país. (CONAB, 2015).

Se observa que las corporaciones del agronegocio han encontrado terreno fértil en el Brasil para la producción de alimentos (soya, maíz y azúcar) y para la producción de agrocombustibles (soya para el biodiesel y caña de azúcar para el etanol), teniendo al Estado como el principal agente de ordenamiento del territorio, ofreciendo crédito, creando infraestructuras relacionadas a la logística (Ferrovía Norte-Sur, la producción de energíaeléctrica (Planta Hidroeléctrica de Belo Monte), entre otras cosas.

La territorialización del agronegocio esta anclada en la apropiación de la tierra, pero también de las aguas superficiales (ríos y lagos) y subterráneas (principalmente extraída del Acuífero Guaraní) utilizadas largamente en la irrigación de las tierras agrícolas y en el procesamiento agroindustrial de las materias primas como la caña de azúcar y la soya. Además por la centralidad que el agua posee para las corporaciones internacionales, Mendonça e Mesquita (2007) elaboraron el concepto de agrohidronegócio para demostrar el modus operandi orquestado por las corporaciones nacionales e internacionales para la reproducción ampliada del capital por medio de la producción de commodities y la exportación del agua y del suelo incorporada en las materias primas exportadas por el país.

La otra dimensión del territorio explorada por las corporaciones internacionales es la extracción de minerales, ello ha desencadenado una reestructuración del marco regulatorio acerca de la exploración del subsuelo brasileño. Desde 2013 este en debate en el Congreso Nacional, el Nuevo Código de Minería, que en la reglamentación busca el privilegio de los intereses del capital privado, sin el dialogo efectivo con las poblaciones tradicionales y campesinas que serán afectadas, como los movimientos sociales que han establecido las (Re) existencias (por ejemplo, el Movimiento de los Afectados por la Minería -MAM)

Además del Nuevo Código, esta siendo debatido el proyecto de ley 1610/96, cuya centralidad es autorizar la minería en tierras indígenas, lo que, si se realiza levantará todavía mas los conflictos con esos pueblos históricamente despojados. Tal coyuntura gana contornos mas drásticos cuando se verifica la formación de un Frente Parlamentario de la Minería, que conforme el estudio de la Comisión Pastoral de la Tierracontabiliza 
224 diputados lo que equivale a 43,66\% de los 513 diputados federales. (CPT, 2015).

Por eso, se considera la minería como componente de la totalidad formada por el territorio, y por consiguiente, en el corazón de la cuestión agraria en la América Latina. La apropiación privada del subsuelo (que institucionalmente se constituye como un bien en la Unión, Art. 20 de la Constitución Federal), por corporaciones nacionales y extranjeras, compone la centralidad en los conflictos agrarios y de clase en el Brasil actual.

La acumulación de capital en México, la disputa de los espacios agrarios y el dominio agroexportador neoliberal

México tiene una superficie geográfica cercana a los 2 millones de kilómetros cuadrados. Con una diversidad climática, geológica, paisajista y cultural, destaca a nivel mundial por ser centro de origen de diversos cultivos entre los que sobresale el maíz.

Con una relación única con la naturaleza, los antiguos mexicanos no sólo aprovecharon el espacio sobre el cual desarrollaron grandes invenciones tecnológicas sino construyeron grandes ciudades como Teotihuacán, México Tenochtitlan, Chichen Itzá, entre otras, que poseen monumentos arquitectónicos que son patrimonio de la humanidad.

A la llegada de los españoles en el siglo XVI, diversos imperios y ciudades-Estado desarrollaban una forma de vida ligada a la agricultura con grandes conocimientos agrícolas, geográficos, arquitectónicos, astronómicos, numéricos, etc. Con la conquista militar, religiosa, económica, biológica y política española inicio el descenso impresionante de la población mesoamericana -que se recuperará hasta el siglo XVIII- y la historia de despojo y explotación de los habitantes originarios.

Pero fue sobre todo en la segunda mitad del siglo XIX -ya con un México independiente- donde el pensamiento liberal europeo llego al poder y comenzó el proceso de expropiación de tierras indígenas para construir grandes haciendas ligadas a la explotación de algodón, de caña de azúcar, henequén, entre diversos productos agrícolas. Fue de tal tamaño el saqueo realizado y el malestar social engendrado, que ello desemboco en la primera década del siglo XX en el levantamiento campesino e indígena más importante de América Latina que fue lo que se conoce hoy como la Revolución Mexicana. 
Gracias a ese movimiento armado, México es de los pocos países de América Latina que pudo construir una reforma agraria parcial que coloco más de la mitad de la tierra en manos de indígenas y campesinos. Producto de ello, se construye el pacto posrevolucionario que da origen al Estado bonapartista mexicano, donde esas masas campesinas e indígenas sustituyeron sus derechos políticos a cambio de su reproducción, con base en la propiedad agraria y el subsidio de la ciudad por parte del campo.

Todo ello construyo en México grandes espacios dominados por la vida campesina e indígena que producía fundamentalmente los alimentos que requerían las familias y el país. Pero sobre todo se constituye una clase campesina que se reproduce socialmente y es reconocida por la sociedad en diferentes dimensiones culturales y políticas.

Armando Bartra (2011, p. 19) lo expresa así:

La palabra campesino designa una forma de producir, una sociabilidad, una cultura pero ante todo designa un jugador de ligas mayores, un embarnecido sujeto social que se ha ganado a pulso su lugar en la historia. Ser campesino es muchas cosas pero ante todo es pertenecer a una clase: ocupa un lugar especifico en el orden económico, confrontar predadores semejantes, compartir un pasado trágico y glorioso, participar de un proyecto común. En especial esto último: participar de un sueño, compartir un mito y una utopía.

Y esos campesinos participaron -con pocas excepciones- en la estabilidad que tuvo México hasta la década de los 80`s del siglo XX, cuando inician las reformas neoliberales de privatización de los bienes públicos, apertura comercial y reducción de los gastos sociales. Todo ese proceso transformo la autosuficiencia alimentaria que había logrado México en la década de los setentas, para abrir paso a los excedentes cerealeros de Estados Unidos y a las importaciones agroalimentarias.

Y pese a la existencia a partir de 1994 del Tratado de Libre Comercio de América del Norte (TLCAN) entre México, Estados Unidos y Canadá, millones de campesinos han resistido el proceso de expropiación de tierras para propuestas agrícolas, mineras, turísticas, ambientales o petroleras.Como han estudiado Luciano Concheiro y Héctor Robles (2014) la propiedad colectiva de la tierra se ha incrementado y el número de campesinos también, pese a todas las visiones catastrofistas del TLCAN.

De acuerdo al Registro Agrario de México (RAN, 2013), 100 millones 235 mil hectáreas se encuentran bajo dominio depropiedad social de la 
tierra, teniéndose más de 4 millones de titulares agrarios y más de 25 millones de mexicanos catalogados como población rural.

Pero también según (Ávila, 2017) el TLCAN ha ocasionado grandes reconfiguraciones territoriales donde observamos procesos de renta y usufructo de las mejores tierras de riego para la producción de frutales o hortalizas, lográndose la subordinación campesina a la agroindustria. Los campesinos trasladan la toma de decisiones sobre qué cultivar, qué cosechar, y qué paquete tecnológico emplear a varios corporativos agroindustriales.

Así una disputa básica de los espacios agrarios se construye entre las empresas agroindustriales ligadas a la exportación de bienes agropecuarios y la producción campesina dirigida a la producción de alimentos para el mercado interno.

Otro elemento de disputa se presenta entre el dominio creciente del capital financiero sobre la esfera productiva lo que trae consigo la aparición de diferentes procesos de especulación inmobiliaria, turística, energética, etc., alrededor de la tierras campesinas e indígenas.

Y por último, en México el dominio agro-energético del territorio se expresa en las grandes disputas que se tienen con diversas corporaciones que buscan explotar pozos petroleros, instalar parques eólicos o solares, utilizar los recursos mineros o promover monocultivos ligados a los agrocombustibles como la Palma Africana, el Piñón o el Sorgo. Además se impulsan -como en Brasil- grandes megaproyectos agro-hidro-energéticos, aeropuertos, ferrovías, autopistas y Zonas Económicas Especiales, que tienen la función de constituir nodos logísticos que faciliten la reducción del tiempo de circulación del capital y con ello la realización de la plusvalía (Ávila, 2017b).

Y es que en la lógica de incrementar sus ganancias los capitalistas recurren a la ganancia extraordinaria por medio de la renta, donde según Moraes y Da Costa (2009, p. 98):

[...] la renta diferencial reposa en las cualidades especificas del lugar, ya sean naturales (como fertilidad del suelo, agua en abundancia) o agregadas por el trabajo humano (localización ventajosa en la distribución urbana o contar con infraestructura y servicios, o cercano a los mercados potenciales), lo que se refleja en una diferencia entre el precio individual de producción de los productores que tienen mejores condiciones (naturales o agregadas) y el precio medio de producción. 
Así por ejemplo, de acuerdo a información del Registro Agrario Nacional (2013) en 11, 459 núcleos agrarios de México (propietarios sociales de la tierra) se llevan a cabo proyecto agropecuarios, mineros, turísticos, ecológicos o industriales, que abarcan una superficie de alrededor de 45 millones de hectáreas, por lo que se observa que cerca de la mitad de la propiedad social se encuentra bajo asedio del capital y la búsqueda de la ganancia mediante la explotación y el despojo.

Jaime Martínez (2018) realiza un análisis sobre los conflictos indígenas que se presentan en México y destacan por el número de ellos, los estados de Chiapas, Oaxaca, Guerrero, Puebla e Hidalgo. Señala claramente que la disputa principal a nivel nacional se encuentra por los desarrollos de proyectos mineros y agrícolas que violan el derecho al territorio y al disfrute de recursos naturales que poseen los pueblos indígenas.

De acuerdo a Carlos Rodríguez (2015) son 1160 proyectos mineros -la mayoría en manos de empresas extranjeras- que se desarrollaban en México en el año 2014, donde la principal característica es su corrimiento espacial hacia el sur de estas corporaciones extractivas ya que anteriormente sólo se les localizaba en el norte del país. El interés de las compañías para invertir en México se debe a que es un espacio geográfico privilegiado ya que es el primer productor mundial de plata, de bismuto el segundo, de plomo y molibdeno el cuarto, de zinc el sexto y de oro el octavo.

México había otorgado para finales de 2014 un total de 44 mil 623 concesiones mineras que abarcaban un área de 36 millones de hectáreas, el $20 \%$ del territorio nacional, de ellas el 50\% están sobre áreas de propiedad social de la tierra por parte de campesinos e indígenas. Entre las empresas mineras destacan GoldCorp. Agnico Eagle, Alamos Gold, Minera Frisco.

Por su parte, la cuestión agropecuaria se enfrenta a la construcción de un modelo exportador agro-alimentario convirtiendo a México en el $12^{\circ}$. Exportador mundial agroalimentario, dedicando más de 24 millones de hectáreas a la producción agrícola y más de 109 millones de hectáreas a la producción ganadera. Entre los principales productos de exportación destacan el aguacate, jitomate y berries a los mercados de Estados Unidos, Japón y Canadá, principalmente. La exportación agroalimentaria es fundamental para la economía mexicana, ya que es la principal fuente de divisas por encima de las remesas, el turismo y el petróleo. De 1980 
a 2016 los cultivos que mas aumentaron su superficie de producción fueron los pastos, el maíz forrajero, agave, limón y avena. (Sagarpa, 2016)

\section{Conclusiones}

Las dos configuraciones que se han desarrollado en AL entre el neodesarrollismo y la continuidad del modelo económico neoliberal, demuestra que el sistema capitalista se ha podido adecuar a los cambios en las matrices productivas.

En el caso del neodesarrollismo el Estado ha retomado de diferentes formas cierto protagonismo en el desarrollo de las fuerzas productivas generando otro tipo de extractivismo, designado por Gudynas (2011) como "neo-extractivismo progresista" que tiene como característica principal el protagonismo de los Estados que con la tutela de los gobiernos que viabilizaron la explotación de los recursos naturales para la exportación pese a los fuertes impactos sociales y/o ambientales.

En este sentido y ejemplificado con lo anterior no es menor, ni periférico, que estas particularidades del contexto actual tienen como soporte tres esferas; el Estado y la política, la ciencia y la tecnología y la comunicación para su mayor aceptación.Sometidos a los intereses del agronegocio que se presenta como la fase moderna del latifundio de monocultivos moderno-colonial, se asiste a la metamorfosis de la producción agrícola en la producción de combustibles con base en la biomasa. Esa es una de las características mundiales del capitalismo y del desarrollo de las fuerzas productivas que el capital impone al mundo, como ha explicado también Porto-Gonçalves (2008).

Y es que las disputas de los espacios agrarios tanto en Brasil como en México no sólo son relevantes por tratarse de las dos principales economías de América Latina, sino porque las resistencias campesinas e indígenas que se construyen, muestran también las posibilidades de construir un mundo más allá de las relaciones capitalistas, que sólo buscan el lucro a través de la destrucción de la naturaleza y la explotación de los seres humanos y la tierra. Esa será la disputa crucial en el siglo XXI. 


\section{Nota}

1 Los zapatistas escriben sobre las 4 ruedas del capitalismo: explotación, despojo, represión y desprecio. (SUB MARCOS, 2013).

2 La empresa Radar fue iniciada en 2008 y tiene como principales acionistas a Cosan S/A, con 19\%, e a Mansilla Participações S/A, subsidiária de la TIAA-CREF, con 81\%, lo que la torna la empresa sócia mayoritaria. El capital indicial de RADAR S.A. era de aproximadamente 400 millones de dólares. (PITTA; MENDONÇA, 2015).

\section{Bibliografía}

ÁVILA, A. R; CARÁMBULA M.; OLIVEIRA, A. R. de; ÁVILA L. Reestructuración capitalista, dominio agro-energético y disputas territoriales en México, Uruguay y Brasil. Revista Argumentos, Ciudad de México, n. 83, p. 17-42, ene/abr. 2017.

ÁVILA, A. Capitalismo y luchas socio-territoriales en Chiapas, México. Revista Geonordeste, São Cristovão, n. 2, p.77-93, Feb. 2017.

ÁVILA, A.; AVILA, L. Las nuevas zonas económicas especiales en México: despojo agrario y resistencia campesina. Revista NERA, Presidente Prudente, São Paulo, v. 20, n. 40, p. 138-162, dez. 2017b.

BARTRA, A. Campesindios: aproximaciones a los campesinos de un continente colonizado. Ecuador: Ediciones La Tierra, 2011.

BORQUEZ, L. C.; BERLANGA, H. R. Tierra, territorio y poder a cien años de lareforma agraria en México: lucha y resistencia campesindia frente al capital. In: ALMEYRA, G. et al. (Coord.),Capitalismo: tierra y poder en América Latina (1982-2012). México: UAM/Clacso/Ediciones Continente, 2014. p. 181-224. (v. III).

BRASIL DE FATO. Terras na região do Cerrado viram alvo de especuladores. Belém, 06 fev. 2017. Disponível em: <https://www.brasildefato.com. br/2017/02/06/terras-na-regiao-do-matopiba-viram-alvo-de-especuladores/>. Acesso em: 08 fev. 2017.

CECEÑA, A. La territorialidad de las corporaciones. In: CECEÑA, A.; ORNELAS, R. (Org.) Las corporaciones y la economía-mundo. 1. ed. México: UNAM-SIGLO XXI editores, 2016.

CONAB. Companhia Nacional de Abastecimento. Acompanhamento Safra Brasileira. Cana, v. 2 - Safra 2015/16, n. 3 - terceiro levantamento, Brasília, p. 1-65, dez./2015. Disponível em: <https://www.cptnacional.org.br/index.php/ component/jdownloads/send/41-conflitos-no-campo-brasil-publicacao/14019conflitos-no-campo-brasil-2015>. Acesso em: 26 jul. 2018.

CPT. Comissão Pastoral da Terra. Cadernos de Conflitos no Campo. Coordenação: Antônio Canuto, Cássia Regina da Silva Luz, Thiago Valentim Pinto Andrade Goiânia. CPT Nacional Goiânia - Brasil, 2015. 240 p. 
CLEMENTS, E. A.; FERNANDES, B. M. Estrangeirização, agronegócio e campesinato no Brasil e Moçambique. In: Observador Rural, n. 6, maio 2013. Disponível em: <http://www.omrmz.org/images/publicacoes/Observador_6. pdf $>$. Acesso em: 16 mar. 2017.

ESCOBAR, A. Senti pensar con la tierra: nuevas lecturas sobre desarrollo, territorio y diferencia. 1. ed. Medellín: Ediciones UNAULA, 2014.

GUDYNAS, E. Más allá del nuevo extractivismo: transiciones sostenibles y alternativas al desarrollo. In: WANDERLEY, F. (Org.) El desarrollo en cuestión: reflexiones desde América Latina. La Paz, Bolivia: Oxfam y CIDES UMSA, 2011. p. 379-410.

HARVEY, D. El 'nuevo' imperialismo: acumulación por desposesión. Socialist Register, v. 10, n, 1, p. 99-129, 2004.

IBARRA, V. Los megaproyectos desde una geografía crítica. In: IBARRA, V.; TALLEDOS, E. (Org.) Megaproyectos en México una lectura crítica. 1. ed. Ciudad de México: UNAM, 2016.

LEVIEN, M. The land question: special economic zones and the political economy of dispossession in India. The Journal of Peasant Studies, v. 39, n. 3-4, p. 933-969, Jul/Oct. 2012.

LEVIEN, M. Regimes of dispossession: from steel towns to special economic zones. Development and Change. v. 44, n. 2, p. 381-407, dec. 2013.

LEVIEN, M. Da acumulação primitiva aos regimes de desapropriação. Sociologia $\&$ Antropologia, Rio de Janeiro, v. 4, n.1, p. 21-53, jun. 2014.

LUXEMBURGO, R. [1913] La acumulación de capital. Ciudad de México: Ed. Grijalbo, 1967.

MARTÍNEZ, J. V. Conflictos indígenas en México: una aproximación. Revista El Cotidiano, Ciudad de México, p. 21-29, ene./feb. 2018.

MARX, K. [1867] El Capital. México, DF: Ed. Siglo XXI, 2004. Tomo I.

MENDONÇA, M. R.; MESQUITA, H. A. O Agro-hidro-negócios no Cerrado Goiano: a construção das (re)sistências. In: ENCONTRO BRASILEIRO DE CIÊNCIAS SOCIAIS E DE BARRAGENS, 2., 2017, Salvador, Bahia. Anais... Salvador, Bahia, 2017.

MITIDIERO JUNIOR, M. A. Violência no campo brasileiro em tempos de golpe. Boletim DATALUTA, n. 114, jun. 2017.

NÚNEZZ, V., CONCHEIRO, L.; COUTURIER, P. Tecnologías mineras que violentan a la madre tierra: subsunción formal y real de los territorios en el capital. Revista Geonordeste, São Cristovão, Ano XXVI, n. 1, p. 197-214, ene./ jul. 2015.

PITTA, F. T.; MENDONÇA, M. L. A empresa Radar S/A e a especulação de terras no Brasil. São Paulo: Rede Social de Justiça e Direitos Humanos, 2015.

PORTO-GONÇAlVES, C. W. P. Amazônia, Amazônias. 3. ed. São Paulo: Contexto, 2001. 
PORTO-GONÇALVES, C. W. P; HOCSMAN, L. D. (Org.). Despojos y resistencias en América Latina/Abya Yala. 1. ed. Ciudad Autónoma de Buenos Aires: Estudios Sociológicos Editora, 2016.

PORTO-GONÇALVES, C. W. P. Otra verdad inconveniente: la nueva geografía política de la energía en una perspectiva subalterna. Polis - Revista de la Universidad Bolivariana de Chile, v. 7, n. 21, p. 105-143, 2008.

REVELLI, M. Crisis del Estado-nación, territorio, nuevas formas de conflicto y de sociabilidad. Viento del Sur, Ciudad de México, n. 11, 1997.

ROBINSON, W. Una teoría sobre el capitalismo global: producción, clases y estado en un mundo trasnacional. 1. ed. Bogota, Colombia: Ediciones desde abajo, 2007.

RODRIGUEZ, C. Geopolítica del desarrollo local: campesinos, empresas y gobiernos en la disputa por territorios y bienes naturales en el México rural. Xochimilco-ITACA: Ed. UAM, 2015. 255 p. (Colección Teoría y Análisis).

RODRIGUEZ, S. Apuntes sobre el pensamiento crítico vs las mutaciones de la hidra en el pensamiento crítico frente a la hidra capitalista. 1. ed. México: EZLM, 2015. Tomo II.

RUBIO, B. El dominio del hambre: crisis de hegemonía y alimentos. 1. ed. México: Chapingo-CP/Juan Pablos Editores, 2014.

SAGARPA. Servicio de Información Agroalimentaria y Pesquera. Atlas Agroalimentario. México, 2016.

TEUBAL, M.; TOMAS, P. Procesos rentísticos y el extractivismo en América Latina. In: GIARRACA, N.; TEUBAL M. (Org.) Actividades extractivas en expansión. ¿Reprimarización de la economía argentina. 1. ed. Ciudad Autónoma de Buenos Aires: Antropofagia, 2013.

XAVIER, C. V.; PITTA, F.T.; MENDONÇA, M. L. Monopólio da produção de etanol no Brasil: a fusão Cosan-Shell. In: Rede Social de Justiça e Direitos Humanos (Org.). Direitos Humanos no Brasil 2011 - Relatório da Rede Social de Justiça e Direitos: Expressão Popular, 2011.

\section{Contribuição dos autores}

Todos os autores ofereceram substanciais contribuições científicas e intelectuais ao estudo. As tarefas de concepção e design do estudo, preparação e redação do manuscrito, bem como, revisão crítica, foram desenvolvidas em grupo. O autor Agustín Avila Romero ficou especialmente responsável pelo desenvolvimento teórico-conceitual inicial; o segundo autor, Adriano Rodrigues de Oliveira, incorporou reflexões sobre o desenvolvimento do campo no Brasil, como o terceiro, Leon Enrique Avila Romero, fizeram acréscimos e correções fundamentais a partir de suas experiências de pesquisa. O texto final expressa um 


\section{trabalho coletivo realizado ao longo de anos de convivência e discussão entre os autores.}

Agustin Avila Romero - Doctor y maestro en Desarrollo Rural por la UAM-Xochimilco, medalla al merito académico de la UAM, Licenciado en Economía, Facultad de Economía de la UNAM. Profesor Visitante en el Instituto de Estudios Socioambientales UFG-Brasil, profesor de Tiempo Completo Universidad Intercultural de Chiapas (UNICH), México. Participa en el Laboratorio de Estudios e investigaciones sobre dinámicas territoriales (Laboter) y el Grupo de Estudios e Investigaciones Trabajo, Territorio y Políticas Públicas (Trappu) de Brasil. Es miembro del Cuerpo Académico Patrimonio, Territorio y Desarrollo en la frontera sur de México. Miembro del Sistema Nacional de Investigadores Nivel 1 Conacyt. Acompañante de movimientos sociales, estudioso de la cuestión agraria, impulsor de procesos de economía solidaria y agroecología y analista de políticas publicas relacionadas con el desarrollo rural y territorial.

Adriano Rodrigues de Oliveira - Graduado con maestría y doctorado en geografía por la Universidad Estatal Paulista (UNESP-Presidente Prudente). Miembro coordinador del Grupo de Estudios e Investigaciones Trabajo, Territorio y Políticas Públicas (TRAPPU), vinculado al Laboratorio de Estudios e Investigaciones de las Dinámicas Territoriales (LABOTER); investigador del Grupo de Estudios e Investigaciones sobre la Dinámica Regional y Agropecuaria (GEDRA) de la Facultad de Ciencias y Tecnología de la UNESP-Presidente Prudente. Realizó una estancia académica en la Universidad de Toulouse, Le-Mirail (Francia). Actualmente es profesor adjunto de la Universidad Federal de Goiás (UFG) vinculado al Instituto de Estudios Socioambientales (IESA), en los cursos de pregrado y posgrado en Geografía, en el campus Samambaia-Goiânia. Tiene experiencia en el área de geografía humana con énfasis en geografía agraria; sus temas de investigación: asociativismo, agricultura familiar campesina (asentados y agricultores tradicionales), agroecología, políticas públicas y desarrollo rural.

Leon Enrique Avila Romero - Doctor en Ciencias Agrarias, maestro en Desarrollo Rural e ingeniero en Agroecología. Miembro del Sistema Nacional de Investigadores CONACYT Nivel 1, líder del Cuerpo Académico Patrimonio, Territorio y Desarrollo en la Frontera Sur de México, línea de investigación Patrimonio biocultural, territorio y agroecología. Ha escrito más de 21 capitulos de libro y 20 artículos científicos. Profesor de Tiempo Completo de la Universidad Intercultural de Chiapas (UNICH). https://orcid.org/0000-0003-1685-0360

Recibido para evaluación el 23 de abril de 2018. Aceptado para publicación el 2 de junio de 2018. 